\title{
Importance of the slick thickness for effective in-situ burning of crude oil
}

van Gelderen, Laurens; Brogaard, Nicholas L.; Sørensen, Martin X.; Fritt-Rasmussen, Janne; Rangwala, Ali S.; Jomaas, Grunde

Published in:

Fire Safety Journal

Link to article, DOI:

10.1016/j.firesaf.2015.07.005

Publication date:

2015

Document Version

Peer reviewed version

Link back to DTU Orbit

Citation (APA):

van Gelderen, L., Brogaard, N. L., Sørensen, M. X., Fritt-Rasmussen, J., Rangwala, A. S., \& Jomaas, G. (2015). Importance of the slick thickness for effective in-situ burning of crude oil. Fire Safety Journal, 78, 1-9.

https://doi.org/10.1016/j.firesaf.2015.07.005

\section{General rights}

Copyright and moral rights for the publications made accessible in the public portal are retained by the authors and/or other copyright owners and it is a condition of accessing publications that users recognise and abide by the legal requirements associated with these rights.

- Users may download and print one copy of any publication from the public portal for the purpose of private study or research.

- You may not further distribute the material or use it for any profit-making activity or commercial gain

- You may freely distribute the URL identifying the publication in the public portal 


\title{
Importance of the slick thickness for effective in-situ burning of crude oil
}

Laurens van Gelderen ${ }^{a}$, Nicholas L. Brogaard ${ }^{\mathrm{a}}$, Martin X. Sørensen ${ }^{\mathrm{a}}$, Janne Fritt-Rasmussen ${ }^{\mathrm{b}}$, Ali S. Rangwala ${ }^{\mathrm{c}}$, Grunde Jomaas $^{\mathrm{a}}$

${ }^{a}$ Department of Civil Engineering, Technical University of Denmark, 2800 Kgs. Lyngby, Denmark

${ }^{b}$ Danish Centre for Environment and Energy, Aarhus University, 4000 Roskilde, Denmark

'Department of Fire Protection Engineering, Worcester Polytechnic Institute, Worcester, MA 01609, USA

\begin{abstract}
In order to improve the potential of in-situ burning (ISB), the importance of the oil slick thickness on two pure oils ( $n$-octane and dodecane) and two fresh crude oils (Grane and REBCO) was studied in relation to the regression rate, boilover tendency, mass loss rate, burning efficiency and flame height. The experiments were performed in a new experimental apparatus, the Crude Oil Flammability Apparatus (COFA), which has been developed to study ISB of oil on water in a controlled laboratory environment with large water-to-oil ratios. The regression rate, average mass loss rate and burning efficiency reached a constant maximum value for all oils at slick thicknesses exceeding 10-20 mm. For thinner initial slick thicknesses, these values were greatly reduced, most likely due to heat losses to the water. A further increase in the initial slick thickness could not improve the burning efficiency above $75 \%$ for the crude oils, showing that it only has a limited effect on the burning efficiency as higher burning efficiencies have been reported for larger scales. Furthermore, the results showed that the burning mechanisms differ for pure and crude oil, indicating that the hydrocarbon mixture in crude oils changes as the burning progresses. This observation merits further research.
\end{abstract}

Keywords: in-situ burning, oil slick thickness, mass loss, burning efficiency.

\section{List of abbreviations}

BE: Burning Efficiency

COFA: Crude Oil Flammability Apparatus

ISB: In-Situ Burning

PGC: Pyrex Glass Cylinder

WMLR: Water Mass Loss Rate 


\section{Introduction}

The burning of crude oils is of great interest as a response method to oil spills, a method known as in-situ burning (ISB) [1-5]. In practice, this response method commonly features the collection of accidently spilled oil on a water surface in a so-called "fire boom", followed by the ignition of the oil slick $[1,6]$ and thereby removing the oil from the water surface. Particularly for potential oil spills in the ice-infested waters of the Arctic, this response method has gained increased attention (see for example Sørstrøm et al. [7], AMAP [8], Nuka Research \& Planning Group [9] and Buist et al. [10]). Due to the relatively minimal logistics of ISB, relatively low costs [11] and its applicability at most levels of ice coverage compared to the more conventional mechanical clean-up methods [9, 12], ISB has a good potential of cleaning up oil spills in the Arctic.

One of the main challenges of ISB is achieving a high burning efficiency (BE), which in this study is defined as the amount of oil (in percentages of the original spill size) removed from the surface of the water during the burning process. While high BEs of up to $99 \%$ have been achieved in both laboratory and large scale field experiments [13-17], lower BEs as low as $40 \%$ have also been reported [18-20]. As these experiments have been performed under widely varying conditions, such as differences in temperatures, oil types, oil amounts and the weathering state of the oils, it is difficult to determine which factors are responsible for these $B E$ variations. In order to gain a better understanding of the factors that influence the BE and what their effects on the burning process are, it is of interest to perform a parametric study of these relevant factors. A more detailed understanding of the burning process and related environmental effects should allow for better informed decisions on whether or not ISB is a favorable response method in case of an (Arctic) oil spill.

Oil spills can be found in a variety of appearances depending on the environment, and the slick thickness can vary greatly from one spill to another. On open sea, oil slicks spread out freely and become as thin as $<1 \mu \mathrm{m}$, also known as oil sheens. In ice-infested water such as in the Arctic, the ice can inhibit the spreading of the oil, allowing it to accumulate to create a thick slick of up to $10-40 \mathrm{~mm}$ [10]. During an ISB operation, the slick thickness can be influenced through the towing speed of the fire boom and the area it encloses (i.e. the distance between the ships) [1]. The oil slick thickness upon ignition is a very important parameter of ISB as it affects many aspects of the burning process. While it is generally accepted that a minimum slick thickness of about 1-3 $\mathrm{mm}$ is required to ignite the oil and to acquire a self-sustaining fire (due to heat loss to the underlying water surface [10]), the importance of a variation in the slick thickness has not been studied in detail. The initial slick thickness has been reported to be the "key parameter" that influences the BE [10]. A thicker slick should lead to an easier ignition and higher BE [10] and thicker slicks might therefore be preferred for ISB.

However, a precise relation between the BE and initial slick thickness is unknown as of yet. Thicker slicks also result in more violent and longer boilovers and can lead to (relatively) more residue formation [10, 21-23]. While boilovers have not been observed during burnings featuring towed fire booms or in waters with currents [10], it is still relevant to take into account for the safety aspects of ISB. The precise physical and chemical mechanisms of boilovers are still largely unknown and hence it is still a somewhat unpredictable phenomenon. 
More residue formation will require a more extensive cleanup after the burning, which would complicate the logistics. Furthermore, due to the spreading of oil on sea, it is often more complicated to gather a certain volume of oil as a thick slick than a thin slick for burning operations. Thus, it is relevant to find an optimal slick thickness that maximizes the beneficial effects on the ignition time and burning efficiency, while minimizing the logistics and safety issues. Therefore, the effects of the initial oil slick thickness on the regression rate, boilover tendency, burning efficiency, flame height and mass loss rate were studied herein to determine the importance of the initial slick thickness for ISB operations.

\section{Materials and methods}

The oil-on-water burning experiments were performed in a newly developed experimental setup, the Crude Oil Flammability Apparatus (COFA), shown in Figure 1 (for more images see Brogaard et al. [24]). The apparatus was developed to represent realistic conditions such that extracted parameters can be transferred directly to field studies. To achieve this, the COFA was designed amongst others to have a large body of water to create an oil-water interface comparable to large scale. These design choices were made to mitigate the complications with heat transfer issues that could be seen in studies with less or no surrounding water $[3,23,25,26]$. While heat transfer models have been used to accommodate for oil-water interface interactions (e.g. [27, 28]), the uncertainties remained significant. The COFA setup was verified against large scale field experiment data from Brandvik et al. [15].

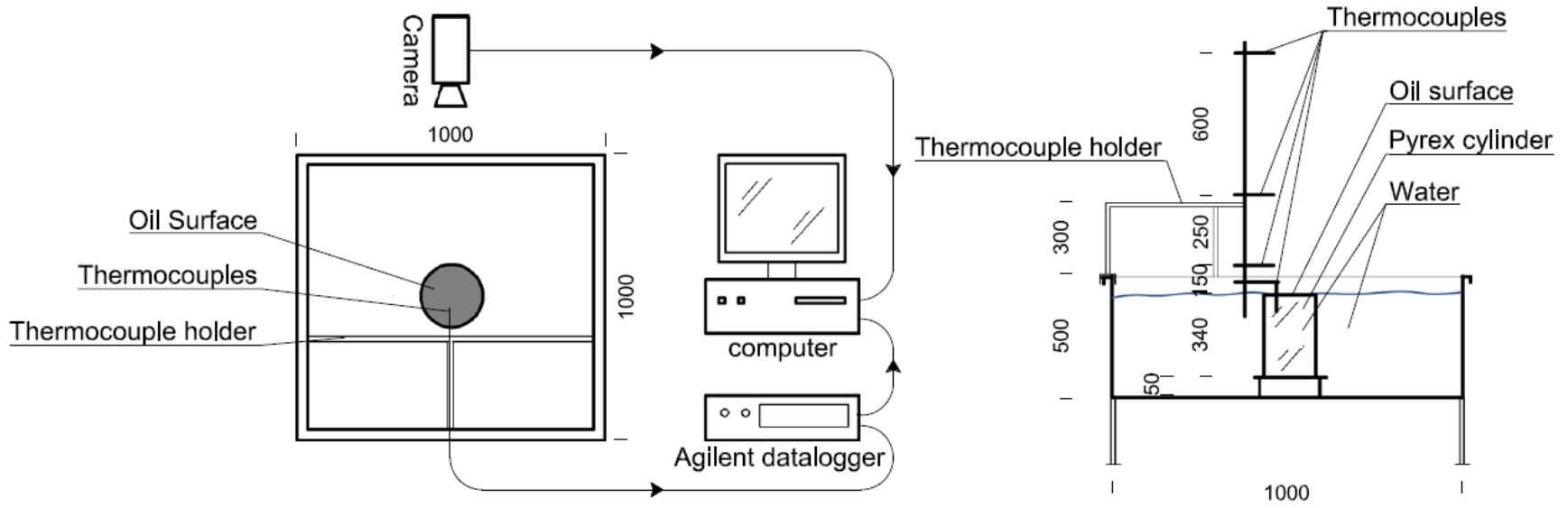



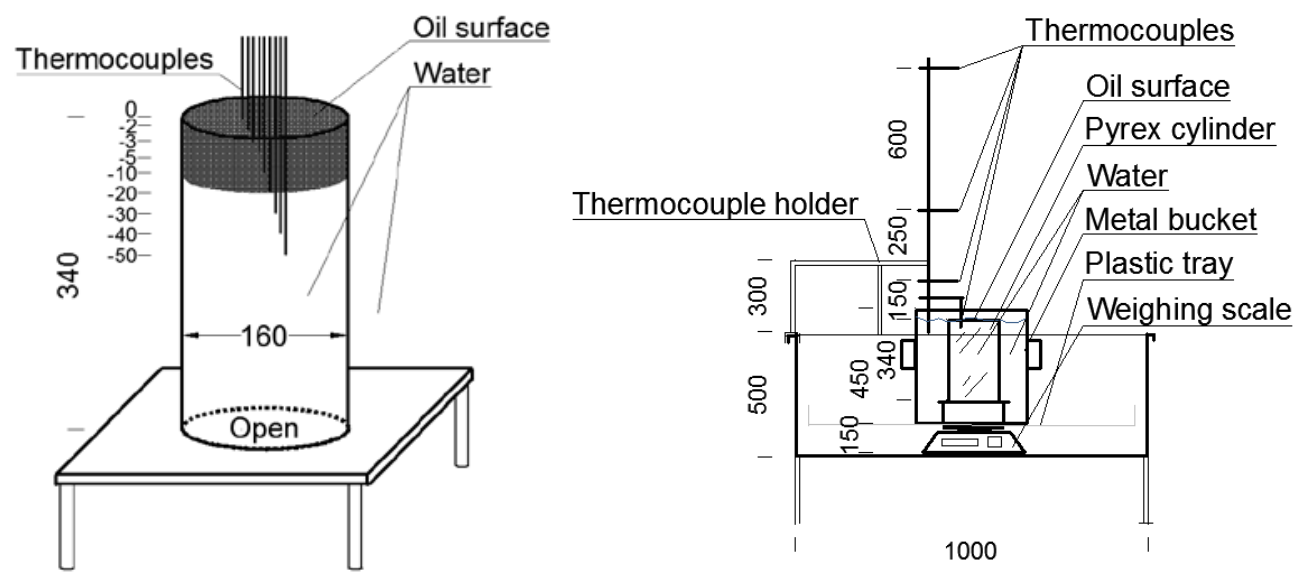

Figure 1. Conceptual outlines of the COFA setup from a top view (top left) and cross sectional view (top right), the PGC on its open steel foot showing the thermocouple distribution and oil layer (bottom left) and the mass loss rate setup in the COFA (bottom right). All numbers are in mm. Adapted from Brogaard et al. [24].

For measuring the regression rate, boilover tendency, burning efficiency and flame height the regular COFA setup was used. The Pyrex Glass Cylinder (PGC), with a height of $340 \mathrm{~mm}$ and diameter of $160 \mathrm{~mm}$, was placed in the middle of a stainless steel water bath of $1.0 \times 1.0 \times 0.50 \mathrm{~m}(\mathrm{~L} \times \mathrm{W} \times \mathrm{H})$ that was placed under an exhaust system. A stainless steel foot for the PGC was used to ensure free water flow underneath, which is important for minimizing the difference in the ullage height throughout the experiment. The bath was filled with water (approximately 390 liters of fresh water of $5-25^{\circ} \mathrm{C}$ ) until it reached about 1-5 cm from the top of the PGC. For the mass loss rate, the COFA setup was adjusted to allow for the use of a scale. The PGC was placed on an open foot in a metal bucket of $0.3 \times 0.3 \times 0.4 \mathrm{~m}(\mathrm{~L} \times \mathrm{W} \times \mathrm{H})$ filled with fresh water of $5-25^{\circ} \mathrm{C}$, which stood on a scale that was covered by an aluminum plate $(0.9 \times 0.9 \mathrm{~m})$ to protect it from liquids ejecting during boilover (Figure 1). The PGC top was at similar height as the metal bucket height to prevent re-radiation from the metal bucket edges.

A total of four different oils were used in the COFA setup, two pure oils ( $n$-octane and dodecane) and two crude oils (Grane and REBCO), of which the most relevant properties are shown in Table 1. For the mass loss setup, the $n$-octane, dodecane and REBCO were used. Slick thicknesses of 2, 5, 10, 20 and $40 \mathrm{~mm}$ were used for the crude oils and slick thicknesses of 3 (due to ignitability issues of dodecane), 5, 10, 20 and $40 \mathrm{~mm}$ for the pure oils. The required amount of oil (corresponding to thicknesses of 2-40 mm) was measured using a scale, and by converting the volume to the corresponding weight by using the density. The oil was then carefully poured on the water surface, after which additional water was added outside the PGC to level the oil surface with the top of the PGC. To measure the temperature profile of the burning oils, a set of 12 thermocouples was placed at $1000 \mathrm{~mm}, 400 \mathrm{~mm}$ and $150 \mathrm{~mm}$ above the oil surface, one thermocouple at the oil surface and eight thermocouples at 2, 3, 5, 10, 20, 30, 40 and $50 \mathrm{~mm}$ below the oil surface (Figure 1). Next, the oil was ignited using a butane torch blower. After the fire extinguished the residue both in and outside the PGC was collected and weighed using hydrophobic absorption pads (see Brandvik et al. [15] for more information on the 
procedure). In general, the reproducibility of the experiments was good, unless specified otherwise. Typically experiments were performed two to three times and showed results within a $10 \%$ variation of the reported data.

\begin{tabular}{|c|c|c|c|c|}
\hline Oil & Density at $25^{\circ} \mathrm{C}(\mathrm{g} / \mathrm{ml})^{a}$ & Boiling point $\left({ }^{\circ} \mathrm{C}\right)$ & Flashpoint $\left({ }^{\circ} \mathrm{C}\right)^{b}$ & Viscosity at $25^{\circ} \mathrm{C}(c P)^{a}$ \\
\hline$n$-Octane & 0.699 & $125-126$ & 13 & 0.386 \\
\hline Dodecane & 0.745 & $215-217$ & 71 & 1.294 \\
\hline REBCO & 0.863 & $300+$ & 23 & 12.400 \\
\hline Grane & 0.934 & $380+$ & $20-21$ & 268.72 \\
\hline
\end{tabular}

To determine the flame height, the experiments were recorded on a black, non-reflecting background with a camera facing the flame in a horizontal fashion (Figure 3). Prior to the experiments, a ruler was placed in the middle of the PGC and a still reference frame was taken with the same resolution as the video to function as a reference between the number of pixels and the height $\left(\mathrm{n}_{\text {pixels }} / \mathrm{mm}\right)$. Videos of the flames were converted to a series of binary pictures with an interval of $0.5-10$ seconds, resulting in $300-600$ data points. The flame height of each picture in $n_{\text {pixels }}$ was then converted to the actual flame height in $\mathrm{mm}$ to obtain the flame height as a function of time. Finally, to reduce the amount of scatter caused by flame puffing, the flame height value of every 10 data points was averaged to represent the average flame height, resulting in a total of $30-60$ displayed data points per experiment.

\section{Results and discussion}

\subsection{Regression rate and the boilover phenomenon}

The regression rate as a function of the initial oil slick thickness for both pure and crude oils is shown in Figure 2. Modelled predictions of the regression rates for $n$-octane, dodecane and crude oil are also shown, using the model developed by Garo et al. [28] and Torero et al. [29] (equation (1)). The average experimental regression rate was calculated from the BE and burning time (from ignition to flame extinction). The BE was directly translated to a corresponding amount of slick thickness that had been removed during the burning. This method neglects any density changes in the crude oils that might affect the actual thickness of the residue. Thus, the experimental regression rate data for the crude oils only show an approximate regressions rate and the trends emerging from the data become the main results. 


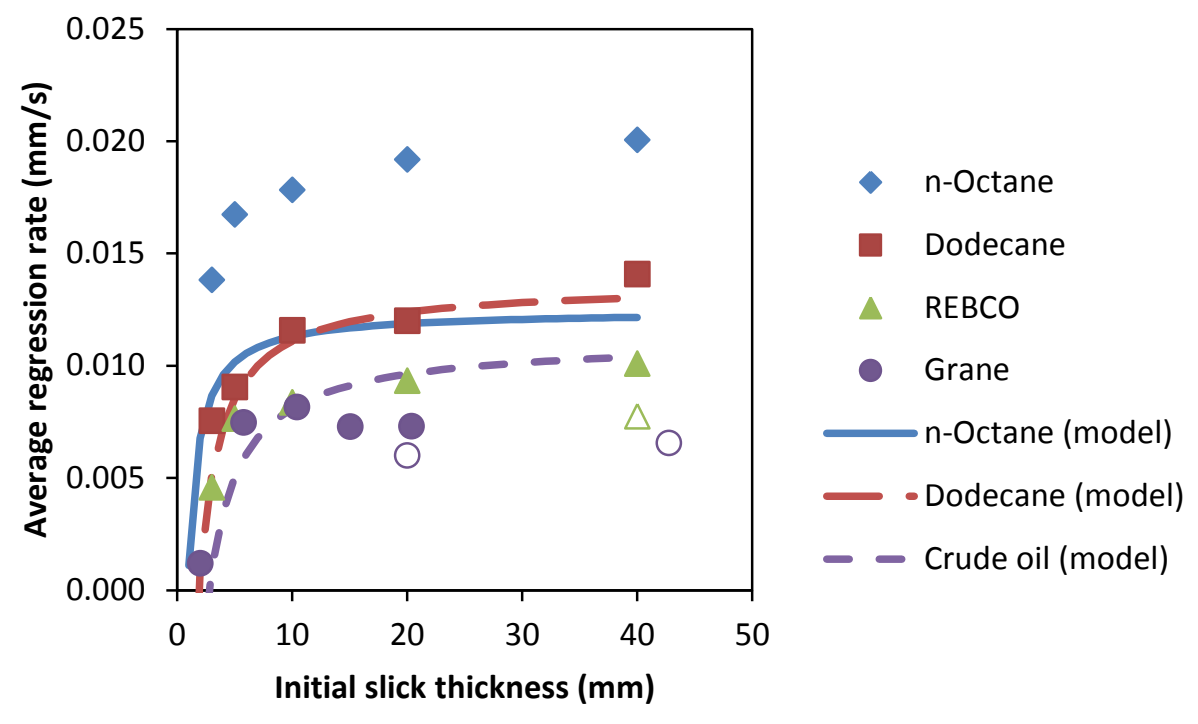

Figure 2. Average regression rates as a function of initial oil slick thickness for the four different oils used in this study. The open symbols represent crude oil experiments without boilover. The Grane data was taken from Brogaard et al. [24].

$$
r=\frac{1}{H_{v} \rho_{F}}\left[\chi\left(\frac{\left(4 \rho_{\infty} C_{p}\left(T_{\infty} g\left(T_{f}-T_{\infty}\right)\right)^{1 / 2}\right)}{\pi}\right) d^{1 / 2}-\frac{a_{F} \lambda_{F}\left(T_{S}-T_{\infty}\right)}{y_{S, i}\left(\sqrt{\alpha_{F}}+\sqrt{\alpha_{W}}\right)^{2}}\right]
$$

The above equation describes the regression rate as a function of the heat feedback from the flame to the fuel surface (first term in the brackets) and heat losses to the water layer based on the thermal properties of the fuel and water (second term in the brackets). Here, $r$ is the regression rate of the fuel, $H_{v}$ the heat of vaporization, $\rho$ the density of the fuel $\left(\rho_{\mathrm{F}}\right)$ and air at ambient conditions $\left(\rho_{\infty}\right), \chi$ the fraction of heat fed back to the fuel surface $\left(2.9 \times 10^{-3}\right.$, from [29]), $C_{p}$ the specific heat, $T_{f}$ the temperature of the flame (in this study taken as $1100 \mathrm{~K}$ based on results in [29]), $T_{\infty}$ the ambient temperature of air, $T_{S}$ the vaporization temperature of the fuel, $g$ the gravitational acceleration $\left(9.81 \mathrm{~m} / \mathrm{s}^{2}\right), d$ the diameter of the pool in meters, $\alpha$ the thermal diffusivity of the fuel $\left(\alpha_{F}\right)$ and water $\left(\alpha_{W}\right), \lambda$ the thermal conductivity and finally $y_{s, i}$ the initial fuel layer thickness. Model input parameters are listed in Table 2 and were obtained from Tanaka et al. [30] and Torero et al. [29]. The crude oil parameters from Torero et al. [29] used to represent both REBCO and Grane were updated with the $\mathrm{T}_{\mathrm{S}}$ and $\rho_{\mathrm{F}}$ of Grane for better representation.

Model calculations showed the same trend for all three oils, i.e. an increasing regression rate with increasing slick thickness that approaches a maximum value, as expected. Altering the flame temperature $\left(T_{f}\right)$ between 900 and $1300 \mathrm{~K}$ did not significantly change the model output qualitatively. Due to the uncertainties concerning the model, changing $T_{f}$ only for quantitative purposes seemed unwarranted. The fact that $n$-octane was predicted to have a lower maximum regression rate than dodecane and experimental data was contributed to 
inaccuracies in the model combined with similar model parameters for $n$-octane and dodecane. The main purpose of showing the modeled predictions is to provide a qualitative reference to which the experimental data can be compared. As the predicted trend for $n$-octane was similar to the other model predictions as expected, it was deemed sufficiently accurate.

\begin{tabular}{lllllll}
\hline \multicolumn{7}{l}{ Table 2. Regression rate model parameters $[29,30]$} \\
\hline Fuel & $T_{S}(\mathrm{~K})$ & $H_{v}(\mathrm{~kJ} / \mathrm{kg})$ & $\begin{array}{l}\lambda\left(\text { at } 20^{\circ} \mathrm{C}\right) \\
(\mathrm{W} / \mathrm{m} \mathrm{K})\end{array}$ & $\begin{array}{l}\rho_{F}\left(\text { at } 20^{\circ} \mathrm{C}\right) \\
\left(\mathrm{kg} / \mathrm{m}^{3}\right)\end{array}$ & $\begin{array}{l}\mathrm{C}_{p}\left(\text { at } 20^{\circ} \mathrm{C}\right) \\
(\mathrm{kJ} / \mathrm{kg} \mathrm{K})\end{array}$ & $\begin{array}{l}\alpha\left(\times 10^{-7}\right)(\text { at 20 } \\
\left(\mathrm{m}^{2} / \mathrm{c}\right)\end{array}$ \\
n-Octane & 399 & 300 & 0.128 & 703 & 2.2 & 0.82 \\
Dodecane & 489 & 256 & 0.137 & 750 & 2.2 & 0.83 \\
Crude oil (Grane) & 623 & 250 & 0.132 & 941 & 2.3 & 0.68 \\
Air & - & - & 0.026 & 1.16 & 1 & 225 \\
Water & 373 & 2257 & 0.59 & 998 & 4.18 & 1.414 \\
\hline
\end{tabular}

The general trend in the data shows that for all oils the regression rate increases with increasing slick thickness and then approaches a fairly constant value. The initial slick thickness at which the constant value is approached varies for each individual oil $(10-20 \mathrm{~mm}$ for $n$-octane, $10-20 \mathrm{~mm}$ for dodecane, $20-40 \mathrm{~mm}$ for REBCO and 20-40 mm for Grane), but it is always larger or equal to $10 \mathrm{~mm}$. This is in accordance with previous reported studies and the trend in model predictions [10, 25, 28, 29]. The low regression rates for slick thicknesses below $10 \mathrm{~mm}$ can be explained by heat losses to the underlying water layer [10, 28]. As the oil functions as an insulating layer between the burning surface and the water surface, a thicker initial slick decreases the heat losses to the water, which in turn causes the regression rate to increase. Increasing the initial slick thickness will therefore minimize the heat losses up to the point where the regression rate reaches a maximum constant value. The obtained maximum values lie within the same order of magnitude as the model predictions and regression rates for pool fires of similar $n$-alkanes reported in literature [31, 32]. The maximum regression rate that an oil can reach is determined by its characteristics (mainly the B-number, also known as the mass transfer number [33,34]) and the pool diameter [23, 25, 28, 29].

While the experimental data mainly follow the expected trends, a few deviations can be seen. The regression rate for Grane seems to peak around $10 \mathrm{~mm}$ after which it reaches a constant value around an initial slick thickness of $20-40 \mathrm{~mm}$. The elevated regression rates for initial thicknesses of 5-15 mm are most likely caused by a boilover just before the flame extinguishes (Figure 3). (Our regression rate data includes boilovers, contrary to the regression rate data from Garo et al. [25] and Garo et al. [28].) During boilover, the regression rate increases significantly and can easily be twice as high as the pre-boilover regression rate [21, 22]. For Grane, boilover was only observed for an initial slick thickness between 5 and $20 \mathrm{~mm}$ and occurred only during half of the $20 \mathrm{~mm}$ experiments. Thus, boilovers likely explain the increased regression rates for initial slick thickness of 5-15 mm compared to $20-40 \mathrm{~mm}$. It is expected that the pre-boilover regression rate as a function of initial slick thickness for Grane follows the same trend as found for the other oils and in previous studies [25, $28,29]$. 


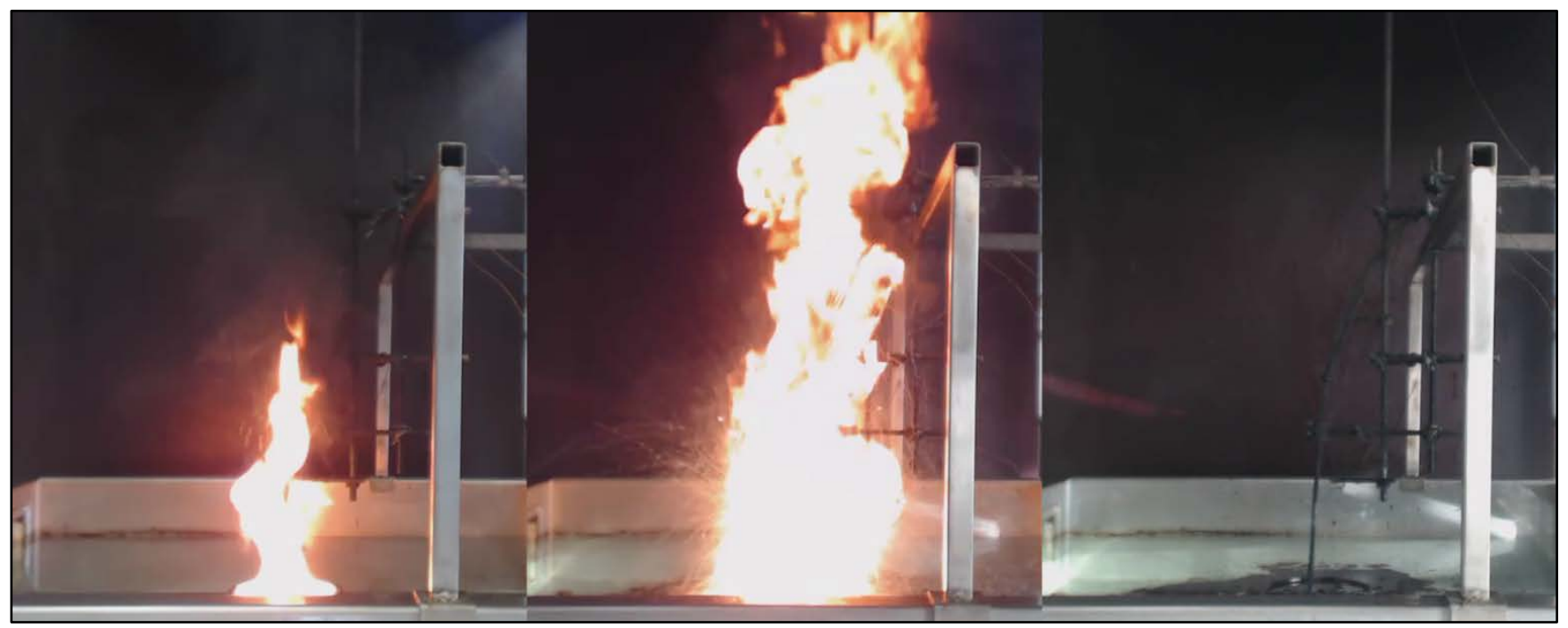

Figure 3. Regular burning of REBCO (left) followed by a boilover (middle) and the resulting spreading of the residue, after flame extinction (right). The frames are $77 \mathrm{~cm}$ wide and $91 \mathrm{~cm}$ high.

The boilover phenomenon is commonly explained by the superheating of the water layer directly under the oil slick [10, 25, 35]. As the burning progresses and the oil slick thickness decreases, the water layer below the oil is heated due to heat transfer through the oil. As the oil layer isolates the water from the air, the water can be superheated, to the point where it reaches a temperature of $120-150{ }^{\circ} \mathrm{C}$. At this point (heterogeneous) nucleation will occur which leads to the violent boiling of the water [36], ejecting water vapor through the oil slick. These ejections also throw liquid oil droplets in the flames, leading to the explosive character of a boilover. Table 3 provides an overview of the boilover occurrences that were observed during the experiments.

\begin{tabular}{llll}
\hline \multicolumn{1}{l}{ Table 3. Boilover characteristics for the tested oils. The Grane data was adapted from Brogaard et al. [24]. } \\
\hline Oil & Min. ignition thickness & Min. boilover thickness & Max. boilover thickness \\
$n$-Octane & $<1 \mathrm{~mm}$ & No boilover occurs & No boilover occurs \\
Dodecane & $2-3 \mathrm{~mm}$ & $2-3 \mathrm{~mm}$ & $40+\mathrm{mm}$ \\
REBCO & $0.8-1 \mathrm{~mm}$ & $2 \mathrm{~mm}$ & $40 \mathrm{~mm}$ \\
Grane & $1.75-2 \mathrm{~mm}$ & $5 \mathrm{~mm}$ & $20 \mathrm{~mm}$ \\
\hline
\end{tabular}

In order to reach a superheated water layer of $120-150{ }^{\circ} \mathrm{C}$, it is essential that the fuel has a boiling point considerably higher than that of the underlying water, i.e. considerably higher than $100{ }^{\circ} \mathrm{C}$. Due to the relatively low boiling points of $n$-octane and dodecane (Table 1), boilover is assumed to be of little or no significance for these pure oils. These assumptions were confirmed in the experiments, where there was no boilover for $n$-octane and only in very limited form for some of the experiments with dodecane. The results for dodecane indicate that its boiling point of approximately $225^{\circ} \mathrm{C}$ lies at the borderline between occurrence and no occurrence of boilover. This borderline was also observed in the oil-water interface temperatures, which 
reached between $100-120{ }^{\circ} \mathrm{C}$ for the dodecane experiments. For comparison, experiments with REBCO and Grane that ended in a boilover reached oil-water interface temperatures of $120-150{ }^{\circ} \mathrm{C}$, while for experiments with $n$-octane featuring no boilover the interface temperature did not exceed $100{ }^{\circ} \mathrm{C}$ (Figure 4). These results correspond well with previous studies on the boilover phenomenon [25, 37].

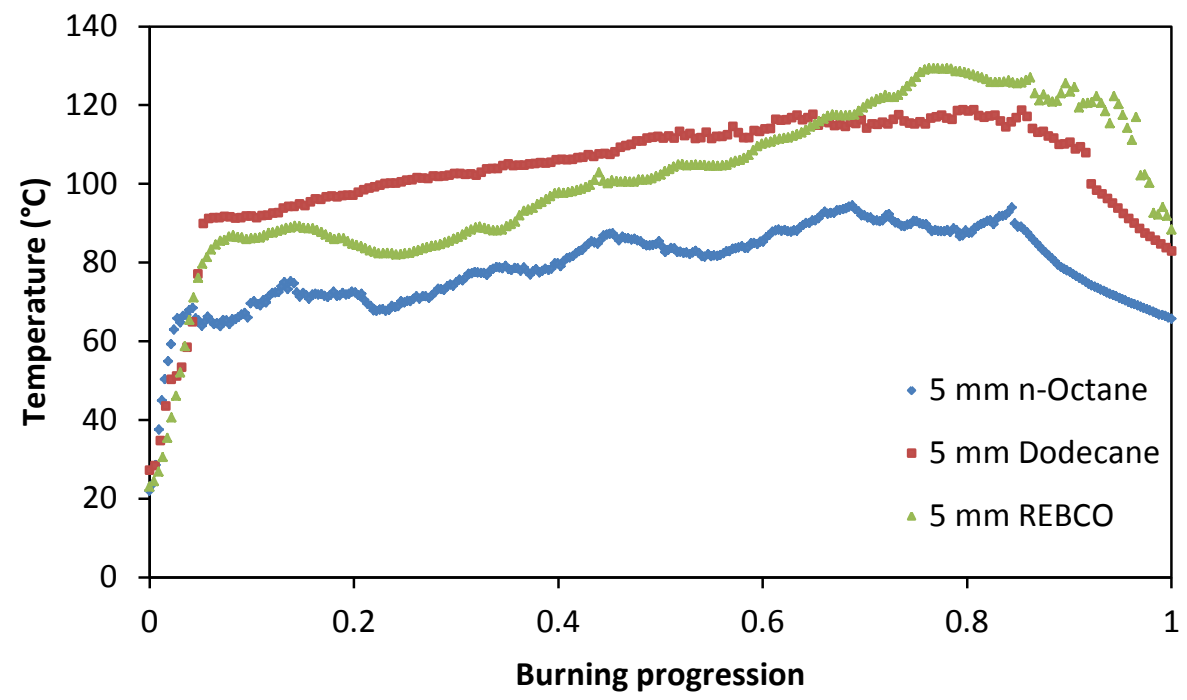

Figure 4. The oil-water interface temperature over the burning progression for n-octane, dodecane and REBCO at an initial slick thickness of $5 \mathrm{~mm}$.

The two data points in Figure 2 for $20 \mathrm{~mm}$ Grane and $40 \mathrm{~mm}$ REBCO represent the experiments with and without boilover. A possible explanation for the failure to boilover is that the oil slick is too thick or becomes too dense during the burning to conduct the amount of heat from the burning surface required for superheating the underlying water layer. It was observed that the obtained residue after the burning is much more viscous (and dense) than the initial crude oil, which could further amplify the insulating effect of the oil slick. Thus, as the viscosity of the slick increases during the burning and the insulating effect increases with thicker initial slicks, a certain initial slick thickness might result in a sufficiently insulating slick to prevent the water from superheating. It seems that this 'boundary thickness' is around $20 \mathrm{~mm}$ for Grane and $40 \mathrm{~mm}$ for REBCO, considering that only half of these experiments went into boilover and no boilover occurred for $40 \mathrm{~mm}$ Grane. The difference in boundary thickness is most likely caused by the properties of the oil (Table 1), e.g. Grane is much more viscous than REBCO.

For the $10 \mathrm{~mm}$ experiments with REBCO and Grane, the boilover was extremely violent and had a significant effect on the $B E$ and regression rate, resulting in more scattered data upon repetition, but the raw data is still matching the presented trend in Figure 2. A possible explanation for the extremity of the boilover is that an initial slick thickness of $10 \mathrm{~mm}$ is sufficiently thick to superheat the water but is not yet functioning as an 
insulating layer. For initial slicks of $2-5 \mathrm{~mm}$ the water layer might already penetrate the oil layer just after it reaches a temperature of $120{ }^{\circ} \mathrm{C}$, instead of heating up to $150{ }^{\circ} \mathrm{C}$, leading to less violent boilovers. For slicks thicker than $10 \mathrm{~mm}$, the insulating effect of the oil (as described above) might hinder the superheating and penetration of the water.

\subsection{Mass loss rate}

The mass loss rate was determined as a function of time for a series of slick thicknesses (2-40 mm) for $n$ octane, dodecane and REBCO, using the mass loss setup as shown in Figure 1. The mass loss data clearly showed that water is also being evaporated during the burning as more weight was lost than the burning residue would suggest (Figure 5). Loss of water occurred during all mass loss experiments and increased with increasing slick thickness (Figure 6). Temperatures of the flame and the slick of individual oil types were comparable regardless of the initial slick thickness and therefore the increase in water mass loss is associated with a longer burning time. Because the water requires time to heat up in order to significantly contribute to the mass loss rate, it has a larger effect on experiments with a longer burning time.

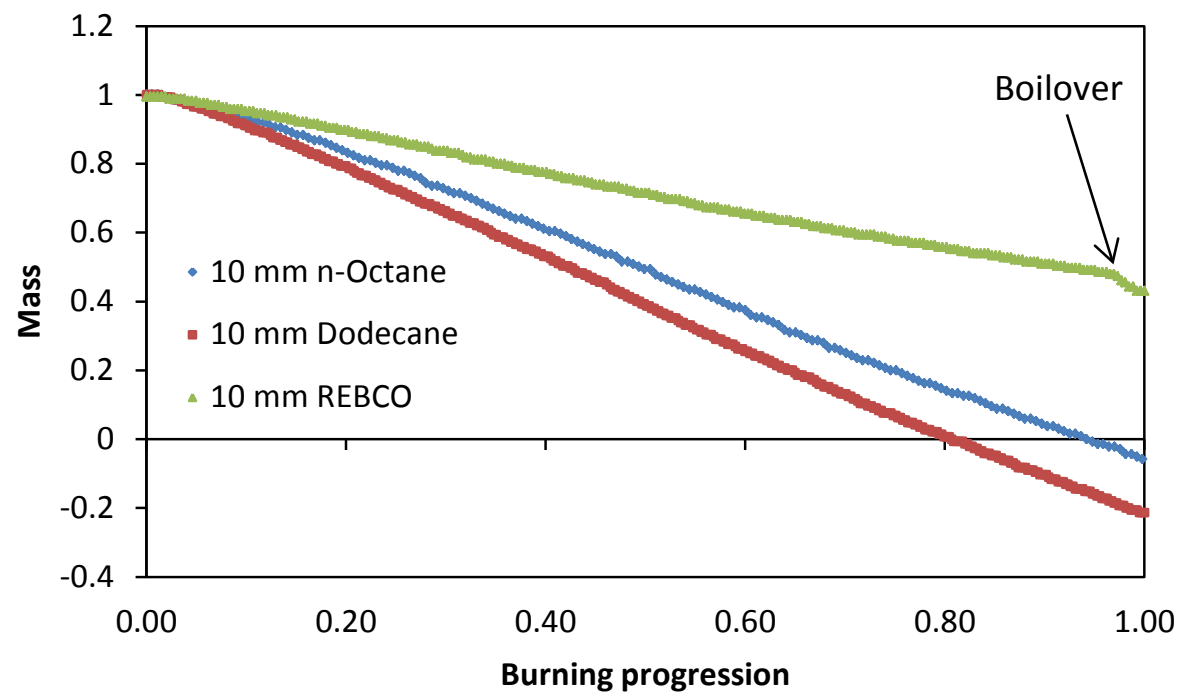

Figure 5. Normalized mass loss curves from ignition to extinction of the flame. The relative mass is based on the initial amount of oil for each experiment.

The boilover phenomenon was also clearly identifiable in the mass loss data. When the boilover was observed, the mass loss rate increased accordingly (as indicated in Figure 5) and a significant amount of (oil) mass was lost in this period. Such a sudden mass loss increases the average regression rate and this confirms that boilover occurrence increases the total regression rate. 
Figure 6 shows an overview of the average mass loss rate in relation to the slick thickness including and excluding the water mass loss. The average mass loss rate was calculated from the mass loss between $10 \%$ and $90 \%$ of the burning time, to avoid the inclusion of the ignition phase, the extinction phase where the burning can become intermittent and the boilover occurrence. The data clearly show that the mass loss rate increases with increasing slick thickness, but the water mass losses distort the trend between the data points from the trend that was observed for the regression rate. The average mass loss data suggests that there is either no maximum mass loss rate, or that the maximum rate is not yet reached. However, considering that the mass loss rate and the regression rate represent similar aspects of the burning process (assuming a constant oil density), the same trend was expected. When excluding the water mass loss (explained in the next paragraph), the data show a good correlation with the regression rate data. Thus, mass loss rates should be corrected for any water mass losses to properly represent the burning of the oil.

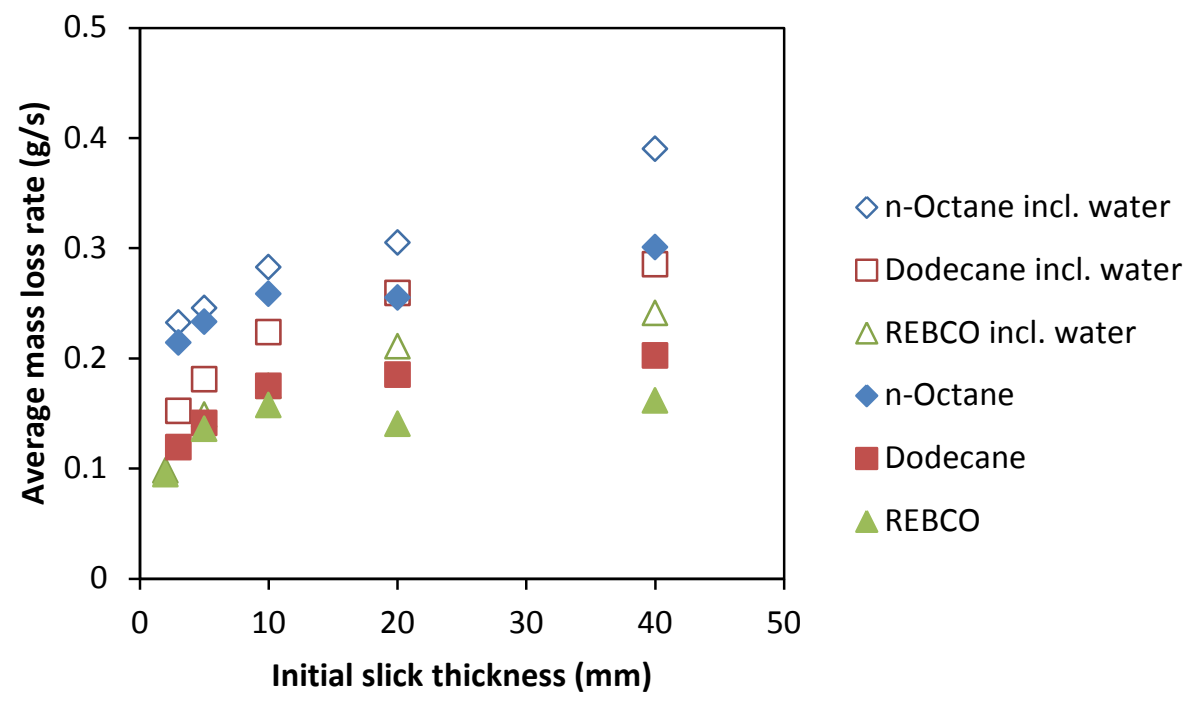

Figure 6. Average mass loss rates of oil and oil including water mass losses as a function of initial oil slick thickness.

In order to see how the burning progresses over time, the average mass loss rate was calculated for 10 segments during the burning, each covering $10 \%$ of the total burning time. To correct for the water mass losses, it was assumed that the water mass loss rate (WMLR) only depends on the burning time and the oil type. Thus, data points of one oil type could be combined to provide five water mass loss data points as a function of time by subtracting the total mass loss with the oil mass lost for each respective data point. In between data points the water mass loss was assumed to be linear and calculated using equation (2), resulting in a WMLR dataset as a function of time. While a linear rate is not necessarily a correct assumption, no data is available on the mass loss ratio between oil burning and water evaporation during the burning and this method at least accounts for a dynamic WMLR for increasing slick thickness. The corrected oil mass loss rate of each 
segment was then calculated based on its time by subtracting the corresponding $W M L R_{m}$. For example, for 10 $\mathrm{mm}$ dodecane the first four segments were corrected with $W M L R_{3}$, the fifth and sixth segment with $\mathrm{WMLR}_{5}$ and the final four segments were corrected with $W M L R_{10}$. The outcome of this method is shown in Figure 7 for the $10 \mathrm{~mm}$ experiments.

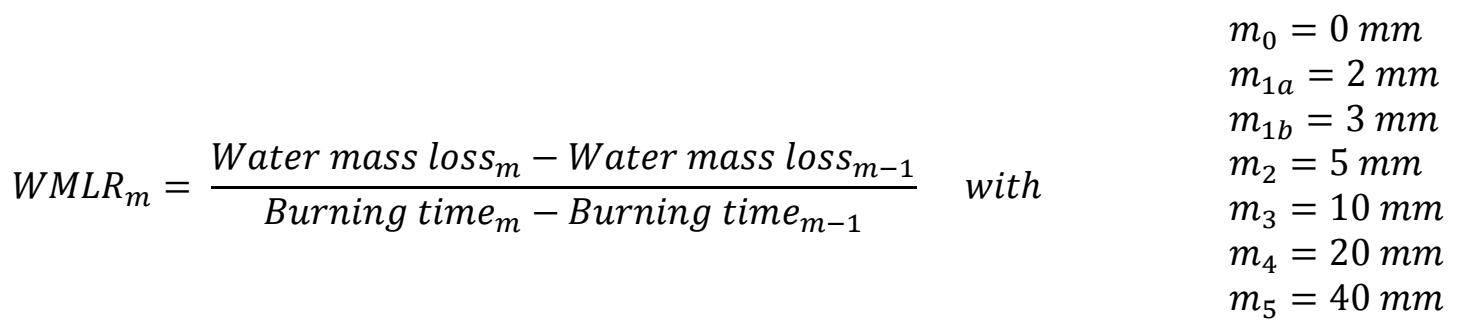

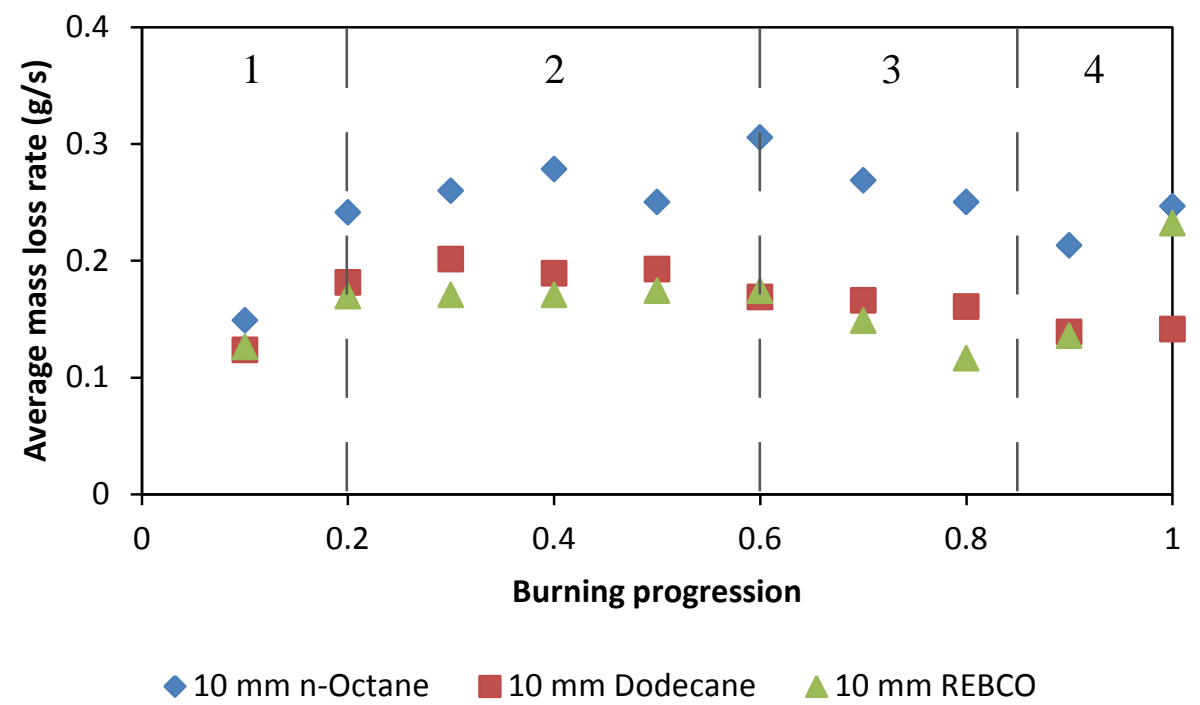

Figure 7. Average mass loss rates (excl. water mass losses) as a function of the burning progression including the four suggested burning phases.

The observed trends in Figure 7 were followed for most of the experiments. After the first segment the mass loss rate increased and remained fairly constant for the first half of the burning. Then, after the fourth to sixth segment the mass loss rate decreased for the second part of the burning until the final segment. At the final segment the mass loss rate would either increase due to a boilover (e.g. REBCO in Figure 7) or continue the trend of the second part of the burning until extinction of the flame (e.g. dodecane in Figure 7). In terms of the actual burning process, these results suggest that the burning can be described in four phases, 1) the startup phase, 2) the steady burning phase, 3) the descending phase and 4) the ending phase which may feature a boilover (Figure 7). Mass loss data for the $40 \mathrm{~mm}$ experiments showed that differences between the second 
and third phase are more present for the crude oil than the pure oils (Figure 8). The mass loss curve of REBCO clearly changes slope, while the pure oils do not show such a significant slope change. A possible explanation is that the composition of the evaporated flammable gas mixture changes during the burning of crude oils, due to (ratio) changes in its hydrocarbon mixture, which is more visible for larger oil volumes.

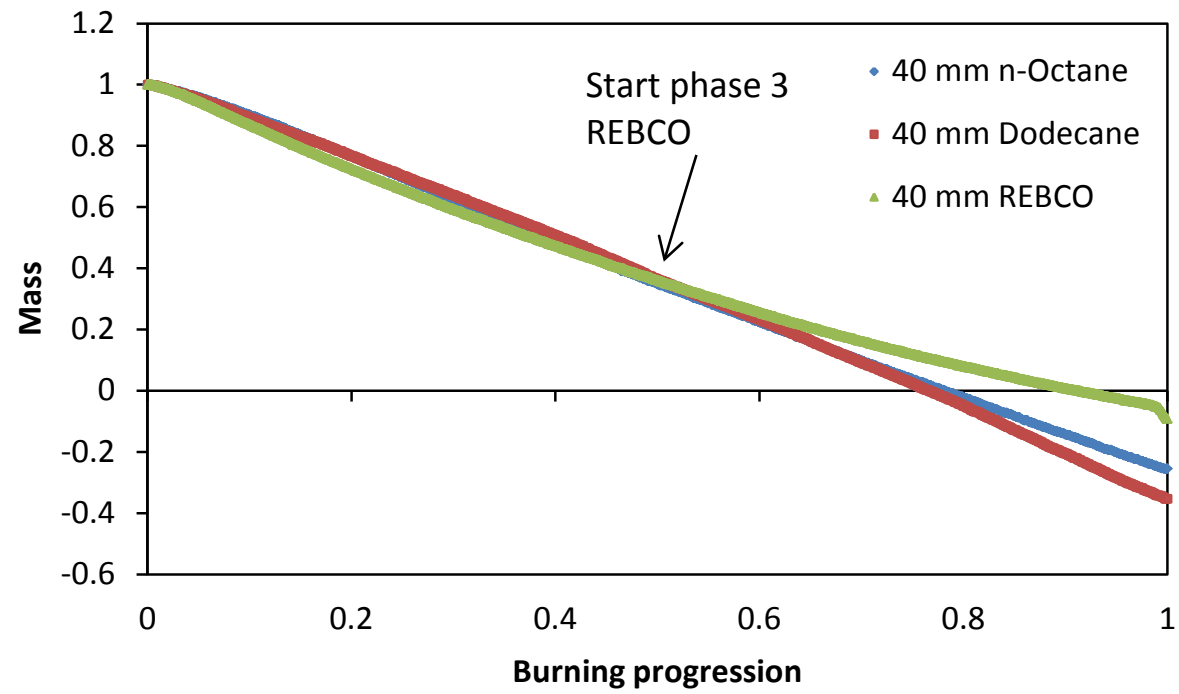

Figure 8. Normalized mass loss curves from ignition to extinction of the flame. The relative mass is based on the initial amount of oil for each experiment.

\subsection{Burning efficiency (BE)}

The BE as a function of initial slick thickness is shown in Figure 9. As expected, the observed trend compares with that for the average regression rate and average mass loss rate. For both pure oils the BE reaches up to $99 \%$, leaving only a very thin colored oil sheen behind. The slightly lower BEs (93-98\%) for thinner pure oil slicks (3-10 $\mathrm{mm})$ are contributed to heat losses to the underlying water layer. For the crude oils, the BE increased with increasing initial slick thickness from $23 \%$ to $75 \%$ for REBCO and from $6 \%$ to $63 \%$ for Grane. The very low BEs for thin crude oil slicks $(2-5 \mathrm{~mm})$ are most likely caused by the fast boilover occurrence after ignition, which stops the burning. This early boilover occurrence can be explained by a combination of fast superheating of the water due to heat losses and a thin slick that allows for the early penetration of water vapor after it is superheated. Thus, while boilover occurrence increases the regression rate and mass loss rate and may increase the BE (e.g. $40 \mathrm{~mm}$ REBCO), it likely has a negative impact on the BE for thin oil slicks.

The difference between BEs for thin and thick slicks is in particular observed for the 10 and 20 mm REBCO results (respectively a BE of $50 \%$ and $71 \%$ ). Usually, the burning time doubled when doubling the slick thickness. However, the typical $10 \mathrm{~mm}$ REBCO experiment took between 550-600 seconds, whereas the $20 \mathrm{~mm}$ 
REBCO experiments took over 1500 seconds. As mentioned in section 3.1, this difference is most likely caused by the insulating properties of the oil slick that prevent the superheated water from penetrating the oil slick. Apparently, the boilover was significantly postponed at an initial slick thickness of $20 \mathrm{~mm}$, which allowed for the burning to continue longer and thus more oil was burned before flame extinction as a result of the boilover. Considering the small difference in BE between 20 and $40 \mathrm{~mm}$ for the crude oils, an initial slick thickness of $20 \mathrm{~mm}$ seems optimal in terms of the BE.

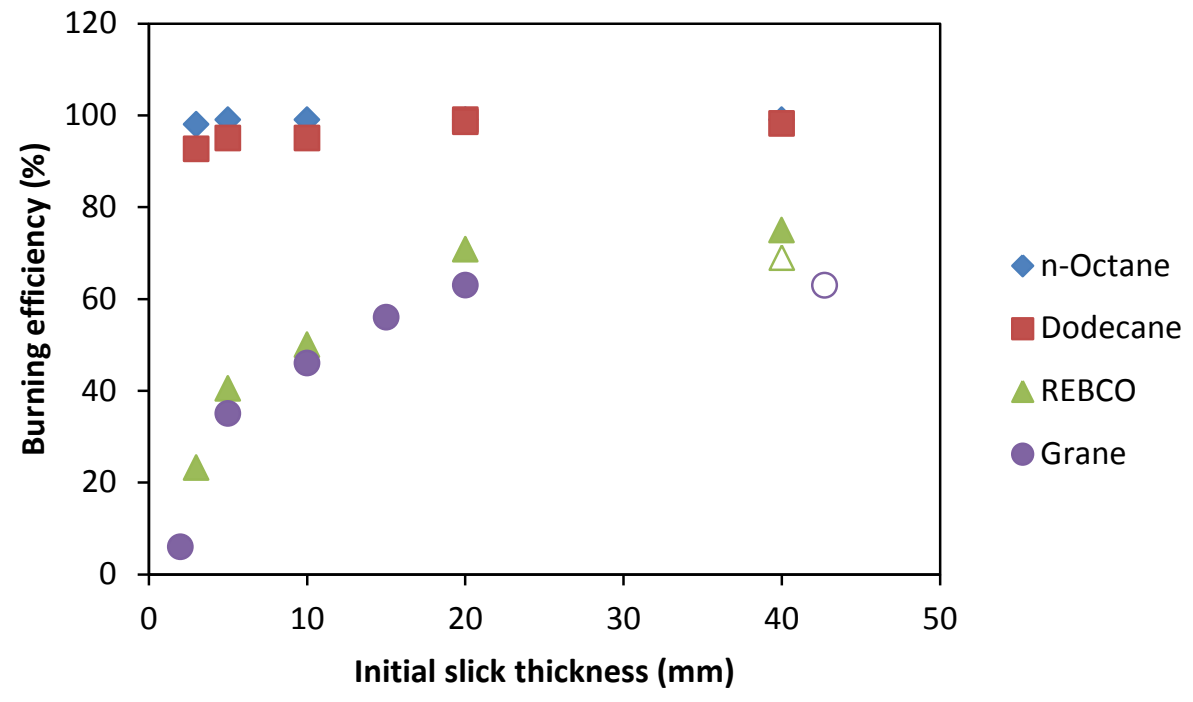

Figure 9. Burning efficiency as a function of initial slick thickness. The open symbols represent crude oil experiments without boilover. The Grane data was adapted from Brogaard et al. [24].

Figure 9 clearly shows that the crude oils do not reach a BE of near $99 \%$. In fact, a minimum residue formation of about $30 \mathrm{wt} \%$ was observed for the 20 and $40 \mathrm{~mm}$ REBCO experiments. Considering that the obtained residues never sank and thus have a density $<1.00 \mathrm{~g} / \mathrm{ml}$, the residues were estimated to have a thickness of 3.5 $\mathrm{mm}$ and $6.5 \mathrm{~mm}$, respectively. Previous studies have described a "rule of thumb" regarding residue formation that states that for an initial slick thickness of $\leq 40 \mathrm{~mm}$, a residue thickness of about $1 \mathrm{~mm}$ is formed $[1,10]$. Based on this theory, a linear increase would be expected for the BE as a function of the initial slick thickness. However, the data clearly show a different trend. While the initial slick thickness has a positive influence on the $\mathrm{BE}$, this is only up to a certain threshold value. Above this $\mathrm{BE}$ threshold value, increasing the slick thickness has no effect on the BE. In other words, based on these small scale experiments, increasing the initial slick thickness does not guarantee an increase in BE.

One of the main differences between the experiments used to establish this rule of thumb and the experiments in this study was the size of the burning area. The experiments in this study had a diameter of $0.16 \mathrm{~m}$, whereas 
some of the studies on which the rule of thumb was based had a diameter of 1.2-17.2 $\mathrm{m}$ and showed BEs up to $99 \%[21,22]$. This size dependency for the BE has also been observed when comparing other large [13-17] and small scale $[16,19,20]$ studies. Large scale experiments are known to have higher regression rates than smaller scales [38, 39], peaking at a diameter of 1-2 $\mathrm{m}$, and it is speculated that the highest BEs can only be obtained for pools above this size. Therefore, the initial slick thickness only has a limited influence on the BE. An infinitely thick slick cannot compensate for the lack of other parameters, such as a large pool diameter.

As mentioned, the trend observed in Figure 9 is likely caused by heat losses to the underlying water layer. For thin slicks, too much of the heat fed back to the fuel surface from the flame is lost to the water to sustain the fire, due to a lack of insulation. Considering that such heat losses play a role independent of the diameter, the same relation between the BE and initial slick thickness is expected for large scale fires. Since larger fires will result in more heat feedback and thus require less insulation to sustain the fire, it is reasonable to expect that the optimal initial slick thickness for large scale fires can be lower than the $20 \mathrm{~mm}$ found in this study. Above this optimal initial slick thickness, which can be as low as the ignitability limit (1-2 mm, Table 3), the BE will be independent of the initial slick thickness. Thus, it is believed that the qualitative findings in this study are applicable to all pool diameters and that for each diameter an optimal initial slick thickness can be found. Because the optimal initial slick thickness is expected to decrease with increasing pool diameter, the effect of the slick thickness on the burning efficiency will therefore also decrease.

A possible explanation for the limited BE observed in this study is that the residue is mainly consisting of the heavy hydrocarbon fractions and that small scale experiments do not generate sufficient heat to burn these. In general, the higher the molecular weight of hydrocarbons, the higher the boiling point becomes. In case the surface temperature of the oil is not hot enough during the burning to gasify the more heavy components in the oil, the fire might be no longer self-sustaining and extinguishes as a consequence. This theory is supported by attempts to reignite the residues which were always unsuccessful. A higher concentration of heavy oil fractions in the residues such as asphalthenes would also explains the observed increase in the viscosity [40]. In addition, one of the main differences between REBCO and Grane is the viscosity (Table 1), which is tightly linked to the asphalthenic percentage in the oil [40] and could explain the difference in BE. As the mechanisms that determine residue formation and thus the BE are not fully understood, more research is required on the combustion mechanisms of crude oils to confirm the proposed theory. Earlier studies have both reported similar $[41,42]$ and different mechanisms $[3,10]$ for crude oil burning, but no general consensus has yet been reached.

\subsection{Flame height}

Flame height profiles as a function of the burning progression for $20 \mathrm{~mm} n$-octane, dodecane and REBCO experiments are shown in Figure 10. The results clearly show that $n$-octane had the highest flame height, followed by dodecane and REBCO, which had the lowest flame heights, independent of the initial slick thicknesses. This trend was also observed in the average flame height, defined as the height up to which $50 \%$ 
of the time flames were present, which was between 385-474 mm for $n$-octane, 325-433 mm for dodecane and 240-312 mm for REBCO.

The difference in flame height between the oils is most likely caused by the difference in mass loss rates (Figure 6 and Figure 7). Higher mass loss rates produce more flammable gases to feed the flames and thus increase the flame height. The rapid decline in flame height for REBCO indicates that the amount of flammable gases produced by the crude oil slick reduces as the burning progresses, more so than for the pure oils, which corresponds with the trends observed for the mass loss in Figure 8. Since the crude oil flame height profile clearly deviates from the pure oil profiles, it is unlikely that this decline is caused by the same mechanism that causes the flame height decline observed in the third and fourth phase of the burning for the pure oils (Figure 5). This observation again suggests that the oil composition changes during the burning, resulting in changes in the mass loss rate. It seems from Figure 10 that more volatile components (that result in a high flame height like $n$-octane) are burned at the start of the crude oil burning, followed by the less volatile components as the burning progresses. These results correspond well with the results on the residue formation discussed above that suggested that the more heavy, and thus less volatile, components mainly make up the residue composition.

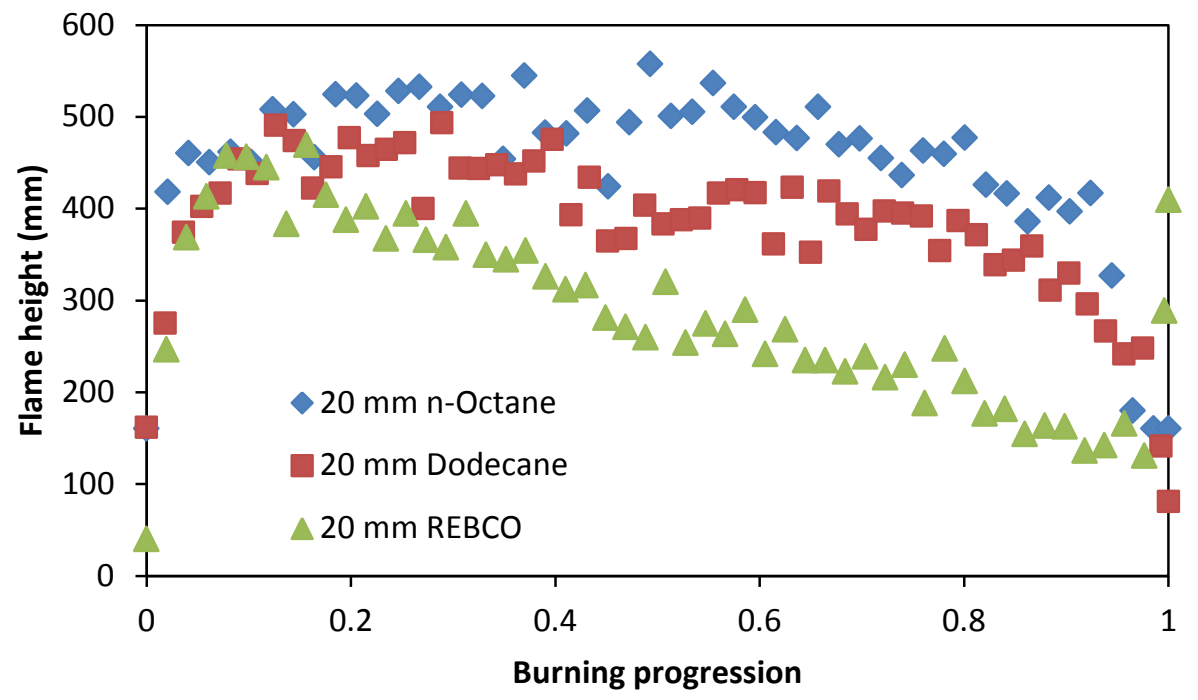

Figure 10. Averaged flame height profiles as a function of the burning progression. Each data point represents the average of ten flame height data points.

For the pure oils, the flame height profiles for all slick thicknesses were very similar to the profile shown in Figure 10. This was in particular the case for initial slick thicknesses of $10-40 \mathrm{~mm}$, suggesting that the flame height is independent of the slick thickness at an initial thickness of $10 \mathrm{~mm}$ or higher. Flame height profiles for 
3-5 $\mathrm{mm}$ experiments showed minor deviations and had an approximately $15 \%$ lower average flame height of 385-408 mm and 325-341 mm for $n$-octane and dodecane, respectively. The flame height reduction for thin slicks is most likely caused by heat losses to the water layer. These results correspond well with the results on the regression rate, mass loss rate and burning efficiency that also indicated that a maximum was reached at an initial slick thickness of $10 \mathrm{~mm}$.

The flame height profiles of the REBCO experiments showed a higher maximum flame height and faster flame height decline with increasing initial slick thickness (Figure 11). The average flame height for REBCO peaked between 5 and $10 \mathrm{~mm}$, possibly due to the differences in the boilover duration. A boilover significantly increased the flame height up to 1000-1200 mm. This made boilover occurrence clearly visible in the average flame height, as shown in Figure 11 at the end of the burning process. The trends in Figure 11 further indicate that the burning progress of REBCO differs from the burning of pure oils, which showed similar flame height profiles independent of the slick thickness. This dependency is most likely caused by a combination of heat losses to the water layer and changes in the composition of the hydrocarbon mixture of the crude oil changes during the burning that lead to a reduced production of flammable gases and thus reduced flame height. The changing oil composition as a function of the burning progression was also suggested to explain the results of the mass loss rate and $\mathrm{BE}$, which adds to the validity of this postulate.

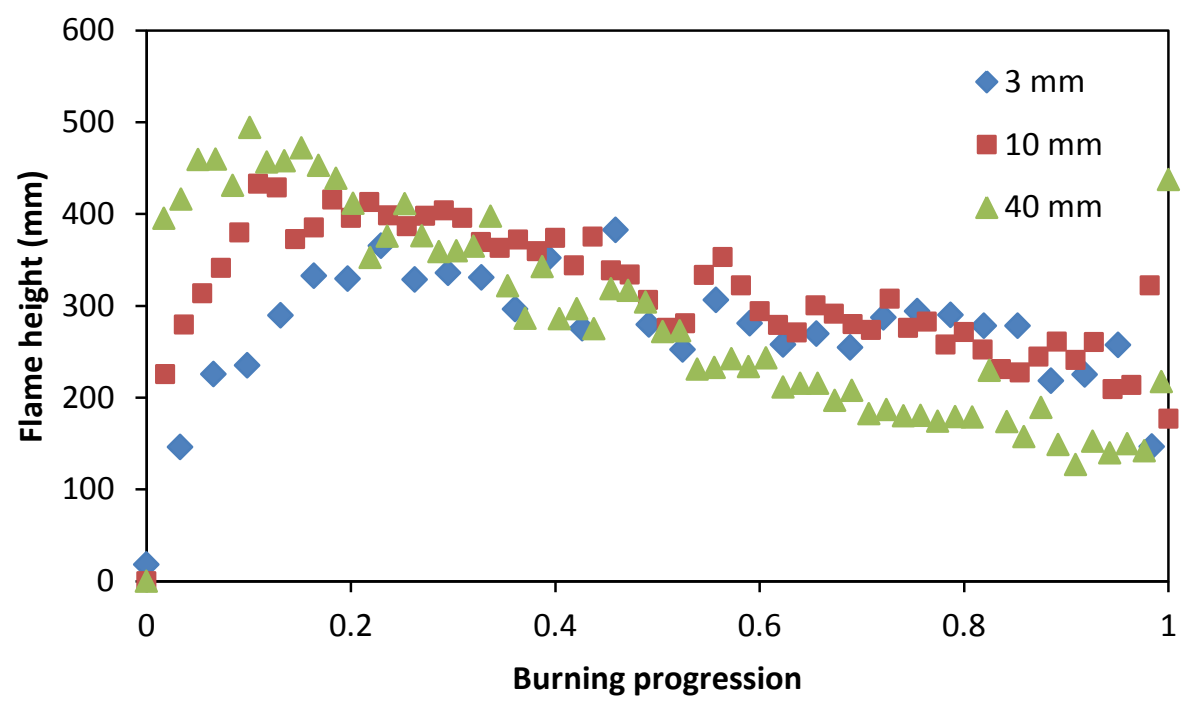

Figure 11. Flame height profiles as a function of the burning progression for various initial slick thicknesses of REBCO. Each data point represents the average of ten flame height data points. 


\section{Conclusions}

The presented results showed a clear relationship between the initial slick thickness and the regression rate, mass loss rate and burning efficiency. Initially, increasing the initial slick thickness resulted in an increase of these burning parameters, up to a certain maximum threshold value after which they remained constant. At this point an optimal initial slick thickness is reached and increasing the slick thickness will not further improve the burning effectiveness. For the studied scale (160 mm diameter pool), the optimal initial slick thickness was $20 \mathrm{~mm}$ with a maximum burning efficiency of $65-75 \%$ for the used crude oils. The highest achievable burning efficiencies of up to $99 \%$ could not be obtained by further increasing the initial slick thickness, suggesting it only has a limited influence on the burning efficiency. The principle of a maximum threshold value is likely independent of the diameter and it is anticipated that for larger scales the optimal initial slick thickness can decrease to a minimum of 1-2 mm. This would further reduce the effect of the initial slick thickness on the burning efficiency, and other factors such as the pool diameter might have an overall stronger effect, considering the much higher burning efficiencies obtained for large scale tests. Therefore, from an operational point of view, it may be sufficient to focus on the initial slick thickness only in terms of ignitability rather than as a means to increase the burning efficiency.

The results of this study also presented additional support for an alternative burning process of crude oils compared to that of pure oils. Results on boilover occurrence, the mass loss rate, the burning efficiency and the flame height all suggest that the composition of the hydrocarbon mixture of the crude oils has to change during the burning in order to explain the observed deviations from the pure oil results. The failure to boilover for thick crude oil slicks is possibly related to an increase in viscosity during the burning. Other results that were possibly related to composition changes in the hydrocarbon mixture were the formation of the burning residue (and therefore the burning efficiency) and the flame height profile. In general, more research is required on the combustion mechanism of crude oils to provide detailed insights on the suggested theories. A better understanding of the combustion mechanisms of crude oils might allow for more precise ISB predictions of untested crude oils, simply based on their hydrocarbon mixture.

\section{Acknowledgements}

The authors would like to thank COWIfonden for funding for the construction of the COFA. The Danish Council for Independent Research (Grant DFF - 1335-00282) funded the overall project. Maersk Oil provided the crude oils that were used in this study. None of the sponsors have been involved in the results and conclusions of this paper. The authors would also like to thank Rolff R. Leisted and W.U. Rojas Alva for their assistance with some of the laboratory work. 


\section{References}

1. Buist, I., J. McCourt, S. Potter, S. Ross, and K. Trudel, In Situ Burning. Pure and Applied Chemistry, 1999. 71(1): p. 43-65.

2. Fingas, M., An Overview of In-Situ Burning, in Oil Spill Science and Technology, M. Fingas, Editor. 2011, Gulf Professional Publishing: Oxford. p. 737-903.

3. Petty, S.E., Combustion of Crude Oil on Water. Fire Safety Journal, 1983. 5(2): p. 123-134.

4. Fitzpatrick, M., U.S. Coast Guard Arctic Pollution Response Research and Development. 1985, United States Coast Guard: Washington D.C. p. 3.

5. SL Ross Environmental Research Ltd. and DF Dickings Associates Ltd., Field Research Spills to Investigate the Physical and Chemical Fate of Oil in Pack Ice. 1987, Environmental Studies Research Funds: Calgary.

6. Potter, S. and I. Buist, In-situ burning for oil spills in arctic waters: State-of-the-art and future research needs, in Oil Spill Response: A Global Perspective, W.F. Davidson, K. Lee, and A. Cogswell, Editors. 2008, Springer Netherlands. p. 23-39.

7. Sørstrøm, S.E., P.J. Brandvik, I.A. Buist, P.S. Daling, D. Dickins, L.-G. Faksness, S. Potter, J. FrittRasmussen, and I. Singsaas, Joint industry program on oil spill contingency for Arctic and ice-covered waters, in Oil in Ice - JIP. 2010, SINTEF: Trondheim. p. 40.

8. AMAP, Assessment 2007: Oil and Gas Activities in the Arctic - Effects and Potential Effects. 2010, Arctic Monitoring and Assessment Programme (AMAP): Oslo, Norway. p. 423.

9. Nuka Research \& Planning Group, LLC, Oil Spill Prevention and Response in the U.S. Arctic Ocean: Unexamined Risks, Unacceptable Consequences. 2010, The PEW Environment Group: Washington, D.C. p. 136.

10. Buist, I.A., S.G. Potter, B.K. Trudel, S.R. Shelnutt, A.H. Walker, D.K. Scholz, P.J. Brandvik, J. FrittRasmussen, A.A. Allen, and P. Smith, In Situ Burning in Ice-Affected Waters: State of Knowledge Report. 2013, Arctic Response Technology. p. 293.

11. Allen, A.A. and R.J. Ferek. Advantages and Disadvantages of Burning Spilled Oil. in International Oil Spill Conference: March 1993. 1993. Tampa, Florida: IOSC.

12. Evers, K.-U., K.R. Sørheim, and I. Singsaas, Oil spill contingency planning in the Arctic Recommendations. 2006: Hamburg.

13. Allen, A.A. Contained Controlled Burning of Spilled Oil During the Exxon Valdez Oil Spill. in Proceedings of the Thirteenth Arctic and Marine Oil Spill. 1990. Edmonton, Alberta: Environment Canada.

14. Fingas, M.F., K. Li, F. Ackerman, M.C. Bissonnette, P. Lambert, R. Nelson, G. Halley, P.R. Campagna, N. Laroche, P. Jokuty, R.D. Turpin, M.J. Trespalacios, J. Belanger, N. Vanderkooy, E.J. Tennyson, D. Aurand, and R. Hiltrabrand. The Newfoundland Offshore Burn Experiment - NOBE. in In Situ Burning Oil Spill Proceedings. 1994. Orlando, Florida: National Institute of Standards and Technology and Minerals Management Service.

15. Brandvik, P.J., J. Fritt-Rasmussen, R. Daniloff, F. Leirvik, and J.L. Resby, Establishing, testing and verification of a laboratory burning cell to measure ignitability for in-situ burning of oil spills, in Oil in Ice - JIP. 2010, SINTEF Materials and Chemistry: Trondheim.

16. Fritt-Rasmussen, J. and P.J. Brandvik, Measuring Ignitability for In Situ Burning of Oil Spills Weathered Under Arctic Conditions: From Laboratory Studies to Large-Scale Field Experiments. Marine Pollution Bulletin, 2011. 62(8): p. 1780-1785.

17. Potter, S., Test of Fire-Resistant Booms in Low Concentrations of Drift Ice - Field experiments May 2009, in Oil in Ice - JIP. 2010, SINTEF: Svalbard. p. 17. 
18. Fritt-Rasmussen, J., In situ burning of Arctic marin oil spills: Ignitability of various oil types weathered at different ice conditions. A combined laboratory and field study, in Department of Civil Engineering. 2010, Technical University of Denmark.

19. Fritt-Rasmussen, J., P.J. Brandvik, A. Villumsen, and E.H. Stenby, Comparing Ignitability for In Situ Burning of Oil Spills for an Asphaltenic, a Waxy and a Light Crude Oil as a Function of Weathering Conditions Under Arctic Conditions. Cold Regions Science and Technology, 2012. 72(0): p. 1-6.

20. Farmahini Farahani, H., X. Shi, A. Simeoni, and A.S. Rangwala, A Study on Burning of Crude Oil in Ice Cavities. Proceedings of the Combustion Institute, 2015. 35(3): p. 2699-2706.

21. Evans, D.D., G.W. Mulholland, H. Gross, H. Baum, and K. Saito. Burning, smoke production, and smoke dispersion from oil spill combustion. in Eleventh Arctic and Marine Oilspill Program (AMOP) Technical Seminar. 1988. Vancouver: BC. Environment Canada.

22. Evans, D.D., W. Walton, H. Baum, K.A. Notarianni, J.R. Lawson, H.C. Tang, K.R. Keydel, R.G. Rehm, D. Madrzykowski, and R.H. Zile. In situ burning of oil spills: Mesoscale experiments. in Fifteenth Arctic and Marine Oilspill Program (AMOP) Technical Seminar. 1992. Edmonton: AB. Environment Canada.

23. Koseki, H. and G.W. Mulholland, The Effect of Diameter on the Burning of Crude Oil Pool Fires. Fire Technology, 1991. 27(1): p. 54-65.

24. Brogaard, N.L., M.X. Sørensen, J. Fritt-Rasmussen, A.S. Rangwala, and G. Jomaas, A new Experimental Rig for Oil Burning on Water - Results for Crude and Pure Oils, in 11th International Symposium for Fire Safety Science. 2014, IAFSS: Christchurch, NZ.

25. Garo, J.P., J.P. Vantelon, and A.C. Fernandez-Pello, Boilover Burning of Oil Spilled on Water. Symposium (International) on Combustion, 1994. 25(1): p. 1481-1488.

26. Walavalkar, A.Y. and A.K. Kulkarni, Combustion of water-in-oil emulsion layers supported on water. Combustion and Flame, 2001. 125(1-2): p. 1001-1011.

27. Hristov, J., E. Planas-Cuchi, J. Arnaldos, and J. Casal, Accidental burning of a fuel layer on a waterbed: a scale analysis of the models predicting the pre-boilover time and tests to published data. International Journal of Thermal Sciences, 2004. 43(3): p. 221-239.

28. Garo, J.P., J.P. Vantelon, S. Gandhi, and J.L. Torero, Determination of the Thermal Efficiency of Preboilover Burning of a Slick of Oil on Water. Spill Science \& Technology Bulletin, 1999. 5(2): p. 141-151.

29. Torero, J.L., S.M. Olenick, J.P. Garo, and J.P. Vantelon, Determination of the Burning Characteristics of a Slick of Oil on Water. Spill Science \& Technology Bulletin, 2003. 8(4): p. 379-390.

30. Tanaka, Y., Y. Itani, H. Kubota, and T. Makita, Thermal conductivity of five normal alkanes in the temperature range 283-373 $k$ at pressures up to $250 \mathrm{MPa}$. International Journal of Thermophysics, 1988. 9(3): p. 331-350.

31. Mudan, K.S., Thermal radiation hazards from hydrocarbon pool fires. Progress in Energy and Combustion Science, 1984. 10(1): p. 59-80.

32. Burgess, D.S., A. Strasser, and J. Grumer, Diffusive burning of liquids in open trays. Fire Research Abstracts and Reviews, 1961. 3: p. 177-192.

33. Emmons, H.W., The film combustion of liquid fuel. ZAMM - Journal of Applied Mathematics and Mechanics / Zeitschrift für Angewandte Mathematik und Mechanik, 1956. 36(1-2): p. 60-71.

34. Drysdale, D., An Introduction to Fire Dynamics. 3rd ed. 2011, New York: John Wiley \& Sons, Ltd. 551.

35. Arai, M., K. Saito, and R.A. Altenkirch, A Study of Boilover in Liquid Pool Fires Supported on Water Part I: Effects of a Water Sublayer on Pool Fires. Combustion Science and Technology, 1990. 71(1-3): p. 25-40.

36. Blander, M. and J.L. Katz, Bubble nucleation in liquids. AIChE Journal, 1975. 21(5): p. 833-848.

37. Garo, J.P., P. Gillard, J.P. Vantelon, and A.C. Fernandez-Pello, Combustion of Liquid Fuels Spilled on Water. Prediction of Time to Start of Boilover. Combustion Science and Technology, 1999. 147(1-6): p. 39-59. 
38. Babrauskas, V., Estimating Large Pool Fire Burning Rates. Fire Technology, 1983. 19(4): p. 251-261.

39. Hottel, H.C., Review - Certain Laws Governing Diffusive Burning of Liquids, by V. I. Blinov and G. N. Khudiakov. Fire Research Abstracts and Reviews, 1958. 1: p. 41-44.

40. Guo, J., C. Chen, H. Wang, N. An, and J. Cao, The Influence of Separated Fractions on Crude Oil Viscosity. Petroleum Science and Technology, 2012. 30(23): p. 2393-2400.

41. Buist, I., K. Trudel, J. Morrison, and D. Aurand, Laboratory Studies of the Properties of In-Situ Burn Residues. International Oil Spill Conference Proceedings, 1997. 1997(1): p. 149-156.

42. Ikegami, M., G. Xu, K. Ikeda, S. Honma, H. Nagaishi, D.L. Dietrich, and Y. Takeshita, Distinctive Combustion Stages of Single Heavy Oil Droplet Under Microgravity. Fuel, 2003. 82(3): p. 293-304. 